\title{
Relative Humidity and the Killing of Bacteria: the Variation of Cellular Water Content with External Relative Humidity or Osmolality
}

\author{
By J. B. BATEMAN, C. L. STEVENS,* W. B. MERCER AND \\ E. L. CARSTENSEN $\dagger$ \\ U.S. Army Chemical Corps, Fort Detrick, Frederick, Maryland, U.S.A.
}

(Received 9 October 1961)

\begin{abstract}
SUMMARY
The paper deals with the relationship between the water content of washed Serratia marcescens and the thermodynamic activity of water, $a_{w}$, over the range $0<a_{w}<1 \cdot 0$. Two overlapping types of measurement are used: osmotic water exchange and water-vapour sorption. The data are given in terms of the equation $w=B m^{-r}$ where $w$ is water content, $m$ is external osmolality (actual or effective, depending upon the technique used), $B$ is a constant and $r$ has values which can be interpreted in terms of the type of process involved: e.g. in the initial stages of osmotic dehydration, $r$ of unity would indicate ideal solution behaviour; in the final stages of drying, any constant value of $r$ would conform to an adsorption function like that of Halsey (1948). The data obtained by the two techniques used fall on a single curve with several zones including $(a)$ non-ideal solution behaviour at high $a_{w}$, (b) two intersecting 'co-operative adsorption' zones at very low $a_{w}$, and $(c)$ a region of variable $r$ where processes such as dissolution of small molecules and 'saturated' swelling of interlinked polymeric structures are presumed to occur. It is thought that detailed interpretation of the unified water uptake curves would be valuable in understanding mechanisms of humidity-dependent loss of viability, in particular the zones of exceptionally rapid attenuation.
\end{abstract}

\section{INTRODUCTION}

This paper presents information on the water content of bacteria at external relative humidities $(\boldsymbol{R H})$ from $100 \%$ to 'zero' as part of a study of humiditydependent losses of viability. It was done partly to fill a need for a means of converting measured 'equilibrium' moisture content values for washed cells to the corresponding $\boldsymbol{R H}$. Further, water transfer curves provide an overall picture which is useful when considering factors of possible significance in cell survival studies.

METHODS

\section{Biological methods}

Bacterial cell suspensions used in sorption measurements : five ml. portions of a $24 \mathrm{hr}$. broth culture of Serratia marcescens strain $8 \mathrm{UK}$ were used to inoculate tryptose agar in Roux bottles. The cells were harvested in distilled water after

* Present address-National Institutes of Health, Bethesda, Maryland. N.Y.

$\dagger$ Present address-Department of Electrical Engineering, University of Rochester, Rochester, 
$24 \mathrm{hr}$. growth at $31^{\circ}$, centrifuged and resuspended in distilled water to give a suspension having about $10^{11}$ viable cells and $67 \mathrm{mg}$. dry residue $/ \mathrm{ml}$. Suspensions used for osmotic volume determinations: these were prepared from frozen cells stored at $-20^{\circ}$, which had been grown in tryptose broth at $30^{\circ}$ and harvested after $28 \mathrm{hr}$. by continuous process centrifuging. They were resuspended in an equal weight of growth medium and frozen in pellets. The pellets, when thawed, had a viable count of about $7 \times 10^{11} / \mathrm{g}$.

The Escherichia coli $\mathrm{B}$ on which osmotic measurements were made was prepared from stock stored at $-20^{\circ}$. The cells had been grown in nutrient broth at $\mathrm{pH} 8 \cdot 1$ and harvested at $18 \mathrm{hr}$. by continuous process centrifuging. After one washing with distilled water they were sealed into small tins and frozen. Before freezing, the total count was $5 \times 10^{12}$, the viable count about $3 \times 10^{12}$ cells $/ g$. dry solids. A single freezing and thawing cycle had negligible effect on viability.

\section{Equilibration of bacterial cells with water vapour}

The experiments were done with the silica spring sorption balance (McBain \& Bakr, 1926) shown in Fig. 1. Freeze-drying and subsequent equilibration with water vapour took place within the same sealed chamber under precisely controlled conditions.

Procedure: (a) Freeze-drying of cells : $1.5 \mathrm{ml}$. of stock suspension was placed in an aluminium foil bucket and frozen in a closed vessel immersed in solid $\mathrm{CO}_{2}$ and alcohol for $30 \mathrm{~min}$. The cold trap in the sorption apparatus, containing water, was immersed in solid $\mathrm{CO}_{2}$ and alcohol. The spring suspension frame, spring, and frozen sample were placed in position (Fig. 1) and the apparatus evacuated. Drying was continued to constant weight, $16 \mathrm{hr}$. being sufficient as a rule. (b) Sorption: the vacuum line was closed and the water reservoir warmed in stages, sufficient time being allowed at each reservoir temperature for constant weight to be reached. At the lower water-vapour pressures this took about $1 \frac{1}{2} \mathrm{hr}$., increasing at higher pressures to about $6 \mathrm{hr}$. because of 'collapse' of the fluffy freeze-dried material and also because of the larger absolute amounts of water to be transferred. Constancy of weight, once reached, was maintained for at least $40 \mathrm{hr}$. (c) Reversibility: loss of water by the rehydrated freeze-dried samples was followed by reversing the sequence of changes of reservoir temperature. $(d)$ Test of performance: the water sorption curve of a specimen of solid egg albumin (not dissolved and freezedried) followed very closely the course described by Bull (1944).

\section{Measurement of water inaccessible to solutes}

Total cell volume $V$ (Fig. 2) was determined by measuring the dilution of a solution of dextran by the intercellular water. Dextran concentrations and leakage from the cells were determined refractometrically (Brice \& Halwer, 1951).

Osmotic water transfer was determined by measuring that portion of a cell pad which was inaccessible to sucrose or phosphate added in sufficient quantity to bring about the desired water movement. In two experiments sucrose and phosphate were added simultaneously, and concordant values for the inaccessible cell volume were obtained from independent analyses for the two substances. The experimental procedure was as follows: cell pads of volume $V_{c}$ containing $g$ gram of dry cells were prepared by centrifuging washed cells (10 ml. distilled water to $1 \mathrm{~g}$. wet cells) 
at $10,000 \mathrm{~g}$. Each pad was resuspended in volume $V_{a}$ of a solution of concentration $c_{a}$ of one of the above solutes. The bacteria were removed by centrifuging and the supernatant of concentration $c_{f}$, containing the original added solution diluted by water in the cell pad, was decanted. In absence of leakage of intracellular solutes, the ratio $c_{a} / c_{f}$ would be simply related to the amount of water in the pellet available to dilute the added solution. There was always a little leakage, and control runs were done by adding $V_{a} \mathrm{ml}$. of water to another cell pad. In separate experiments

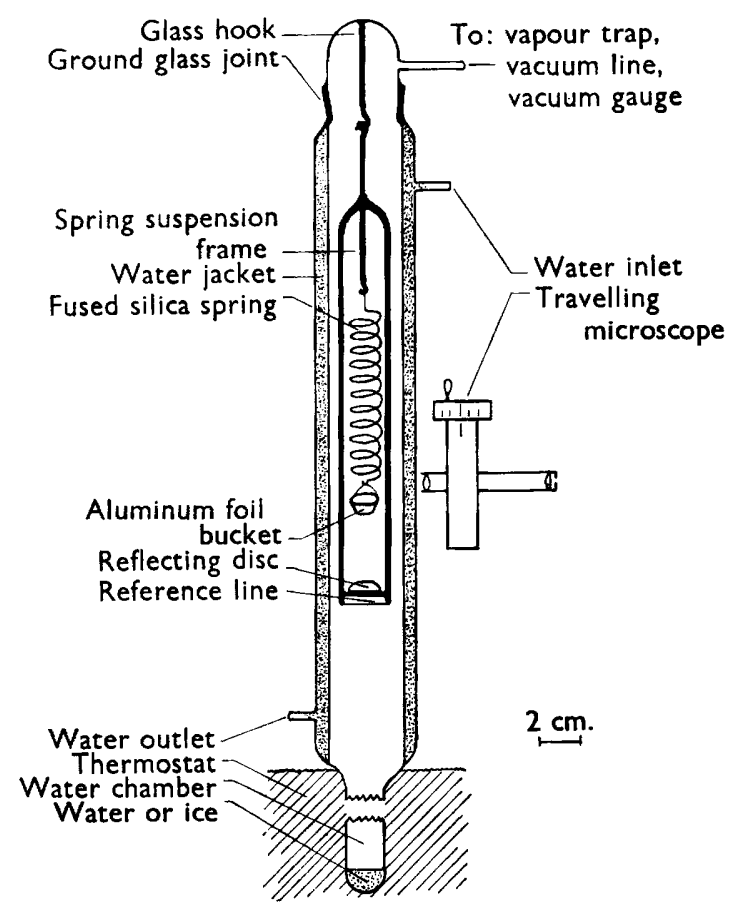

Fig. 1. Silica-spring sorption balance used to measure equilibration of bacterial cells with water vapour. Bacterial sample is in aluminium foil bucket. Changes in weight of the sample are measured by observing movement of the bucket with respect to a thin reference wire on the spring suspension frame, using a travelling microscope independently mounted. Changes of $0.03 \mathrm{mg}$ could be detected. Absolute vapour pressure of water $p$ above sample is determined by temperature of water or ice in cold trap at bottom of apparatus, while relative vapour pressure or water activity is determined by the ratio of $p$ to the saturation vapour pressure of water $p_{0}$ at the temperature of the jacket surrounding the sample chamber. Direct thermal exchange between sample and cold trap is minimized by having constant temperature water flowing doronward through jacket, and by a reflecting disk below sample.

it was found that the leakage of substances containing phosphate from the bacteria was a function of the ionic strength of the environment. Thus when phosphate was being used to measure inaccessible volume, the control run was done with a $\mathrm{KCl}$ solution of initial concentration $c_{a}$ instead of pure water. If the concentration $c_{0}$ of the supernatant from the sample represents the increment in $c_{f}$ caused by leakage, the true dilution factor is $c_{a} /\left(c_{f}-c_{0}\right)$ and the volume inaccessible to the solute in question, $V^{\prime} \mathrm{ml} . / \mathrm{g}$. dry cells, is given by

$$
g V^{\prime}=\nabla_{c}+V_{a}\left(c_{f}-c_{0}-c_{a}\right) /\left(c_{f}-c_{0}\right) \text {. }
$$


For dextran, $c_{0}$ varied from 0.08 to $0.5 c_{f}$ as the salt concentration was increased; for sucrose, $c_{0}$ varied from 0.06 to $0.03 c_{f}$ as the sucrose concentration was increased; for phosphate, $c_{0}$ was 0.01 to $0.06 c_{f}$.

Sucrose analyses were made in the differential refractometer at $5461 \AA$. Phosphate was determined by the Fiske-SubbaRow method as modified by Boltz \& Mellon (1947). In converting the analytical data for the equilibrium continuous phase to external osmolalities, use was made of the osmotic coefficient values of Stokes (1945) for phosphate and Scatchard, Hamer \& Wood (1938) for sucrose.

\section{THEORY}

\section{The cell model}

Representing the bacterial cell by an osmotically sensitive protoplast and cell wall, the volume subdivisions are portrayed in Fig. 2.

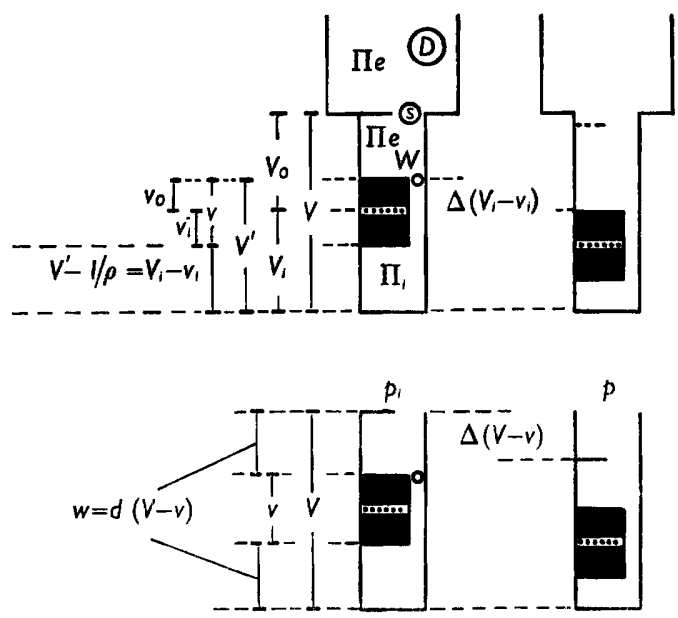

Fig. 2. Volume subdivisions of bacterial cell (not to scale). Upper left, fully hydrated cell immersed in solution of osmotic pressure $\Pi_{e}$. Upper right, cell partly dehydrated osmotically. Lower left, fully hydrated cell free of extracellular liquid equilibrated with water vapour at partial pressure $p_{1}$ close to saturation. Lower right, cell partially dehydrated by equilibration with water vapour at partial pressure $p$ equivalent osmotically to the external solution used to produce osmotic dehydration in upper right. In all diagrams horizontal dots represent cytoplasmic membrane and black areas are cell solids of total weight $1 \mathrm{~g}$. Solids above membrane belong to cell wall, those below membrane to cell interior. The corresponding volumes of solids and aqueous subdivisions are shown on the left and are self-explanatory. In upper left diagram, the wide area above the 'organism' represents a suspending medium containing dextran, $D$, sucrose, $S$, and water, $W$. The 'gateway' to the cell wall is large enough to admit molecules of $S$ but $D$ is excluded. The gateway to the osmotically sensitive part of the organisms, the channel to the right of the cell solids, will not admit $S$ or $D$ but is freely permeable to $W$. The symbols in the middle, $\Delta\left(V-v_{i}\right)$ and $\Delta(V-v)$, represent the volume changes actually measured by osmotic water distribution measurement and by water sorption measurements, respectively.

\section{Notation}

The following symbols will be used in addition to those in Fig. 2.

$a$, constants in the BET, Halsey, and logarithmic isotherms; $a_{w}$, water activity or relative vapour pressure $p / p_{0} ; B$, constant in equation (18); $c$, constants in the 
BET and logarithmic isotherms; $d$, density of water; $f$, a factor used in comparing water sorption data with osmotic volume changes, equation (16); $m$, molality, moles/1000 g. water. Subscript $e$ refers to external medium, $i$ to phase within cell osmometer; $m^{\prime}$, osmolality, $\nu \phi m$ for electrolytes, $\phi m$ for simple non-electrolytes; $M_{w}$, molecular weight of water; $n_{i}$, moles of osmotically active solute in osmotically sensitive volume $V_{i}$ (Fig. 2); $p, p_{0}$, vapour pressures of water over an aqueous solution and over pure water, respectively; $r$, mole ratio; moles of a solute per mole of water (equation 6), $r$, a constant in Halsey's isotherm and in equation (18); $R$, gas constant, $8 \cdot 3144$ joule deg. ${ }^{-1}$ mole $^{-1} ; R H$, relative humidity, $100 a_{w} ; T$, absolute temperature; $w$, water content of washed bacteria equilibrated with a vapour phase, g./g. dry cells; $\theta$, fraction of water adsorption sites occupied by water; $\Pi$, osmotic pressure; $\rho$, density of dry bacterial cell solids; $\phi$, molal osmotic coefficient of solvent, equations $(2),(7) ; \nu$, number of ions into which a strong electrolyte dissociates.

\section{Osmotic water transfer}

The osmotic pressure equations (see Dick, 1959) for the osmotically responsive portion of the cell and for the ambient solution of reference substance, respectively, are

$$
\begin{gathered}
\Pi_{i}\left(V_{i}-v_{i}\right)=n_{i} \phi_{i} R T, \\
\Pi_{e}=m_{e} \phi_{e} d R T / 1000=m_{e}^{\prime} R T / 1000 .
\end{gathered}
$$

Assuming osmotic equilibrium between the interior and exterior of the osmometer and the absence of any hydrostatic pressure difference,

$$
\begin{gathered}
m_{e}^{\prime}=m_{i}^{\prime}, \\
\log \left(V_{i}-v_{i}\right)=\log \phi_{i} n_{i}-\log m_{e}^{\prime}+\mathbf{3} .
\end{gathered}
$$

Ideal behaviour would be represented by a straight line of unit slope, while lines of any other slope or of varying slope would indicate variation of $\phi_{i} n_{i}$ with external osmolality, failure to achieve osmotic equilibrium, or intrusion of a hydrostatic pressure term.

\section{$A$ sorption isotherm equivalent to equation (5)}

A sorption isotherm is usually a plot of water content $w$ against water activity $a_{w}$. In order to describe the whole course of cell water exchange a convenient parameter is the osmolality $m_{e}^{\prime}$ since this can be given a formal value for any water activity by way of Bjerrum's definition of the osmotic coefficient (Guggenheim, 1957)

It follows that

$$
\ln a_{w}=-\phi \Sigma r
$$

$$
\ln a_{w}=-10^{-3} \phi m M_{w}=-0.01806 m_{e}^{\prime} \text { and } m_{e}^{\prime}=-127 \cdot 83 \log a_{w} .
$$

The description of sorption data by an equation equivalent to (5) would be the same as using an isotherm of the form

$$
\begin{gathered}
\log (V-v)=A-\log \left(-\log a_{w}\right), \\
A=\log \phi_{i} n_{i}+0 \cdot 8934 .
\end{gathered}
$$




\section{$A$ modified equation (5) for sorption data}

The so-called logarithmic adsorption isotherm (De Boer, 1956)

$$
\ln a_{w}=\theta / c^{\prime} R T
$$

has been widely used for chemisorption, while for physical adsorption Halsey's (1948) equation can be written

$$
\ln a_{w}=-a / R T \theta^{1 / r} .
$$

Using the subscript 1 to mean completion of a monolayer of water $(\theta=1)$, we can put

giving

or, from (7),

$$
-a / R T=\ln \left(a_{w}\right)_{1} \text { and } \theta=(V-v) /(V-v)_{1}
$$

and

$$
\ln a_{w}=\theta^{-1 / r} \ln \left(a_{w}\right)_{1}
$$

$$
m_{e}^{\prime}=\theta^{-1 / r}\left(m_{e}\right)_{1}
$$

The corresponding equation for osmotic volume change is (5), which can be applied to the water volume of the whole cell by assuming

so that

$$
V-v=f\left(V_{i}-v_{i}\right)
$$

$$
\log (V-v)=-\log m_{e}^{\prime}+\log \phi_{i} n_{i}+\log 1000 f
$$

where $\phi_{i}$ is a function of $m_{e}^{\prime}$. Comparing (15) and (17),

$$
\begin{gathered}
\log (V-v)=-r \log m_{e}^{\prime}+\log B, \\
B=\left(m_{e}^{\prime}\right)_{1}^{r}(V-v)_{1}, \\
\phi_{i} n_{i}=B m_{e}^{\prime(1-r)} / 1000 f .
\end{gathered}
$$

Equation (18) is applicable wherever a straight line is obtained by plotting $\log (V-v)$ against $\log \left(m_{e}^{\prime}\right)$. With unit slope $(r=1)$, ideal solution behaviour is indicated; otherwise, $\phi_{i} n_{i}$ varies according to equation (20). In the 'osmotic' region this can be attributed to increase of osmotic coefficient with increasing $m_{e}^{\prime}$ if $r<1$, rather than to a change of $n_{i}$. If the line is curved, equation (18) does not hold, because $(a)$ the functional dependence of $\phi_{i}$ upon $m_{e}^{\prime}$ does not follow equation $(20)$, or $(b) n_{i}$ varies with $m_{e}^{\prime}$ because of leakage, precipitation, or dissolution, or (c) a hydrostatic term is omitted. The behaviour of $r$ in the sorption region is discussed later.

\section{Application of equation (18) to inaccessible volume data}

'The 'osmotic' cell volume $V^{\prime}$ is measured by a dilution technique. It comprises water within the osmometer and the entire dry volume of the cell, and reference to Fig. 2 will show that $\left(V_{i}-v_{i}\right)$ is not directly comparable to $(V-v)$. To reconcile osmotic and sorption data, the assumption is made (equation 16) that the water fraction and osmotic coefficient are the same for the osmotically responsive part of the cell as for the whole cell. The factor $f$ can be obtained from dextran and sucrose impermeable volumes for standard conditions (subscript $s$ ); by inspection of Fig. 2,

$$
f=\left(V_{s} \rho-1\right) /\left(V_{s}^{\prime} \rho-1\right)
$$




\section{RESULTS}

\section{Sorption experiments}

A sorption cycle taken at $20^{\circ}$ is illustrated in Fig. 3 ; the characteristic hysteresis will be noted. Any progressivechange in the specimen during the lengthy experiment was ruled out by checking a few individual points with fresh cell samples. The points at the highest $\boldsymbol{R H}$ values $\left(p / p_{0}\right.$ around 0.99$)$ are of course of little significance, for maintenance of an $R H$ of $99 \%$ at $20^{\circ}$ in these experiments depended upon maintaining a steady temperature difference between the main chamber and reservoir of only $0 \cdot 15^{\circ}$. The results of experiments at $36^{\circ}$ resemble those at $20^{\circ}$ in accuracy and general appearance. The data refer to essentially non-viable cells; the fractional viable recovery after freeze-drying was about $10^{-1}$, that at the end of a 14-day experiment about $10^{-10}$.

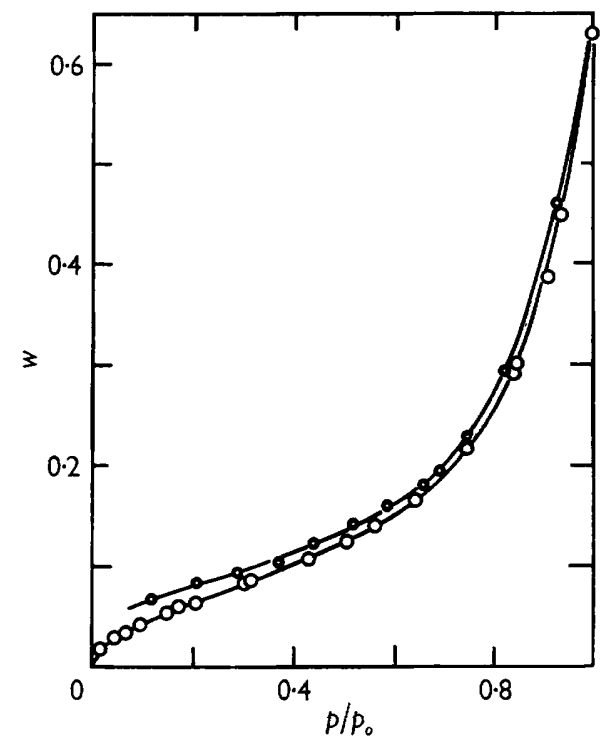

Fig. 3. Water sorption and desorption curves of Serratia marcescens at $20^{\circ}$. Abscissa, relative aqueous vapour pressure or water activity. Ordinate, grams sorbed water per gram dry weight of organisms. Open circles, water uptake; small heavy circles, water loss.

The data conform over the usual range ( $R H 10$ to $45 \%)$ to the BET equation (Brunauer, Emmett \& Teller, 1938)

$$
a_{w} / w\left(1-a_{w}\right)=\left(1+c a_{w}-a_{w}\right) / a c .
$$

Values of the constants $a$ and $c$ are given in Table 1.

\section{Osmotic shrinkage of cells in sucrose and phosphate solutions}

The dilution measurements gave values of the cell volume inaccessible to the added solute, $V^{\prime} \mathrm{ml}$./g. dry solids. The cell water of Serratia marcescens and Escherichia coli $\mathrm{B}$ inaccessible to the solute was taken to be $V^{\prime}-\mathbf{0 . 7 6 3}$, assuming the density of the dry residue to be $1 \cdot 31$. This was converted by equation (16) into 


\section{Table 1. BET constants* for bacteria and proteins}

See text equation (22). The constant $a$ is usually interpreted as the weight of a complete monolayer of water in grams per gram dry material. The constant $c$ is dimensionless and is related exponentially to the heat of adsorption of the water monolayer expressed in multiples of $R T$.

\begin{tabular}{|c|c|c|c|c|c|c|c|}
\hline & & \multicolumn{2}{|c|}{ D 1} & \multicolumn{2}{|c|}{ S1 } & \multicolumn{2}{|c|}{ D2 } \\
\hline & & $a$ & $c$ & $a$ & $c$ & $a$ & $c$ \\
\hline $\begin{array}{l}\text { Serratia } \\
\text { marcescens }\end{array}$ & $20^{\circ}$ & $\rightarrow$ & 一 & 0.069 & $10 \cdot 5$ & $0 \cdot 069$ & $52 \cdot 4$ \\
\hline $\begin{array}{c}\text { Pseudomonas } \\
\text { aeruginosa† }\end{array}$ & $30^{\circ}$ & 0.064 & $35 \cdot 5$ & - & 一 & - & 一 \\
\hline $\begin{array}{l}\text { Staphylococcus } \\
\text { aureus } \dagger\end{array}$ & $30^{\circ}$ & $0 \cdot 054$ & $48 \cdot 5$ & - & 一 & - & - \\
\hline & & & $a$ & c & & & \\
\hline Egg albumin $\ddagger$ & & & 0.0615 & $11 \cdot 60$ & & & \\
\hline Stretched nylon $\ddagger$ & & & $0 \cdot 0176$ & $5 \cdot 97$ & & & \\
\hline Collagen & & & 0.0952 & $17 \cdot 80$ & & & \\
\hline
\end{tabular}

* Brunauer, Emmett \& Teller (1938).

$\dagger$ Imelik (1951), desorption of wet cells.

$\$$ Bull (1944), average of adsorption and desorption at 25 and $40^{\circ}$.

D 1 indicates first desorption of wet cells. S1 is the first sorption of water by freeze-dried cells and $\mathrm{D2}$ is the succeeding desorption.

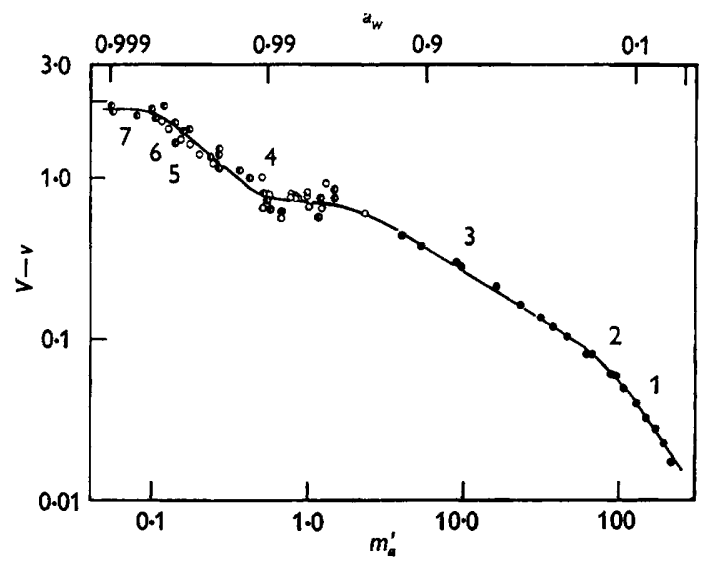

Fig. 4

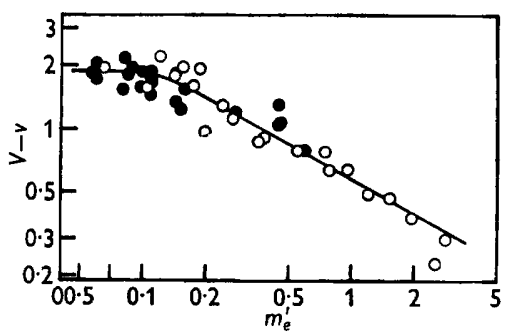

Fig. 5

Fig. 4. Water volume of one gram dry Serratia marcescens as a function of environmental osmolality. Lower scale of abscissae: actual or effective external osmolality. Upper scale, water activity or relative humidity $\times 1 / 100$. In osmotic shrinkage experiments the actual external osmolality is determined by the nature and concentration of added solutes, and the recorded water volumes are corrected for the presence of the cell wall, which does not participate in the osmotic shrinkage (see text). In water sorption experiments the cell water is measured directly as a function of water activity in the vapour phase, and the corresponding effective osmolalities are calculated by text equation (7). Open circles: data obtained with added sucrose. Half-closed circles: with added sodium dihydrogen phosphate. Closed circles: sorbed water.

Fig. 5. Water volume of $1 \mathrm{~g}$. dry Escherichia coli as a function of environmental osmolality. Open circles: data using added sucrose; closed circles: added sodium dihydrogen phosphate. See also legend to Fig. 4. 
total cell water, $(V-v)$, per g. dry residue, using for $V_{s}$ the volume inaccessible to dextran (for $S$. marcescens, 3.38 and for $E$. coli $2.65 \mathrm{ml} . / \mathrm{g}$.) and for $V_{s}^{\prime}$ the volume inaccessible to sucrose (for $S$. marcescens, $2 \cdot 49$, for $E$. coli $2.00 \mathrm{ml} . / \mathrm{g}$.). Application of equation (21), with $\rho$ equal to $1 \cdot 31$, gives $f=1 \cdot 52$ for both cell types.

\section{Combined osmotic and sorption data}

The data for Serratia marcescens are given in Fig. 4. There appear to be three distinct regions of approximate conformity to equation (18), for which the appropriate values of the 'constants' $r$ and $B$ are assembled in Table 2. The osmotic shrinkage data for Escherichia coli are similarly plotted in Fig. 5 while the corresponding numerical data are included in Table 2.

\section{Table 2. 'Constants' and limits of linear water exchange curves of bacteria}

See text equations (18) and (20) and Fig. 4. Column (1) identifies the linear region in Fig. 4, corresponding to slopes given in column (4). These zones extend over the range of external osmolalities in column (3) and the corresponding ranges of water volume are shown in column (2). Column (5) gives the values of the 'constant' $B$ used in calculating the osmotic coefficients $\phi_{i}$ of column (7) and the apparent number of moles of osmotically active intracellular solutes per gram.

(1)

Zone

Serratia marcescens

1 , monolayer sorption

3 , multilayer sorption

5 , osmotic shrinkage

Escherichia coli

5, osmotic shrinkage

E. coli*

5 , osmotic shrinkage

Staphylococcus aureus*

5 , osmotic shrinkage

\section{(2)}

$(V-v)$

$\mathrm{ml} . / \mathrm{g}$. dry cells
(3)

$m_{a}^{\prime}$

$0.02-0.05$
$0 \cdot 1-0.5$
$1 \cdot 0-2 \cdot 2$
0.8
2.2

$2 \cdot 2$

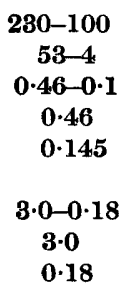

1.2-3.55

$$
1 \cdot 2
$$

$\mathbf{3 . 5 5}$

$0 \cdot 76-2 \cdot 24$

$\mathbf{3} \cdot \mathbf{0}-\mathbf{0} \cdot \mathbf{3}$
$\mathbf{3} \cdot \mathbf{0}$
$\mathbf{0} \cdot \mathbf{3}$

3.0-1.0

\section{(4)}

$r$

$\mathbf{1} \cdot 20$

$0 \cdot 60$

0.82

0.82

$0 \cdot 82$

0.55

0.55

0.55

$\mathbf{0 . 5 0}$

0.50

0.50

$1 \cdot 00$
(5)

B

(6)

$10^{3} n_{i}$

(7)

$\phi_{i}$

* Calculated from data of Mitchell \& Moyle (1956). See text.

\section{DISCUSSION}

Continuity of osmotic and sorption data. Figure 4 represents both osmotic shrinkage and water sorption of washed Serratia marcescens. Since there is no discontinuity, our assumption that the water relationships of the osmotically responsive portion are not greatly different from those of the organism as a whole is probably a reasonable one. The compatibility of the two sets of data also suggests that at the highest humidities equilibrium was attained, despite the difficulty of maintaining nearly saturated atmospheres (Ashpole, 1952).

Zones of water transfer. The following zones can be recognized in Fig. 4 : (1) water monolayer formation; (2) transition to multilayer adsorption; (3) multilayer water uptake; (4) transition to osmotic swelling; (5) osmotic swelling; (6) transition to constant cell volume; (7) limiting cell volume. 
Zone (1). Formation of a monolayer. This is a steep linear region terminating when about $0.063 \mathrm{~g}$. water has been taken up per g. dry cells. Similar initial phases have been noted in other processes, for example, in the adsorption of water on anatase (Halsey, 1948). The inflexion presumably signals completion of a monolayer of water, since the value 0.063 agrees quite well with the BET constant $a$ (Table 1). Similar values of $a$ have been obtained by Imelik (1951) for other micro-organisms (Table 1). They are fairly typical of an average protein; indeed our Serratia marcescens curves are scarcely distinguishable from that of egg albumin. It is therefore likely that all the cell solids are accessible to water vapour and that the sorption curves at low $R H$ values are essentially those of the bacterial protein and nucleic acid which together comprise perhaps $90 \%$ of the dry cell mass. If there are significant contributions from proteins of more extreme types, such as collagen and silk, these must average out. The sorbed monolayer is not readily removed (Fig. 3) as seen in the different BET constants $c$ for sorption and desorption (Table 1), the latter having values comparable to those of Imelik (1951) for the initial drying of wet cells.

Zones (2) and (3). Multilayer adsorption. After a short curved transition, there is a straight line of reduced slope $(r \sim 0.6)$ which extends to $a_{w}$ about 0.92 . This covers the range of the cases illustrated by Halsey (1948) and interpreted by him in terms of co-operative (multimolecular) adsorption upon a non-uniform surface.

Zone (4). Transition from co-operative adsorption to osmotic swelling. With continued application of equation (18) $\theta$ would approach $\infty$, with gross condensation of water. Instead, the slope $r$ decreases, perhaps because of an intermolecular structure which limits the expansion of the cell solids. This would be equivalent to a decrease in the effective area of adsorbent.

This region of the sorption curve overlaps the curve of osmotic dehydration. Evidently, at $\boldsymbol{R H}$ values high enough to distend the hydrophilic cell structures to their maximum extent, some or all of the small molecular solutes have dissolved, and the further course of events with increasing $R H$ is best considered in terms of the osmotic coefficient $\phi_{i}$. As the $R H$ increases from 80 to 99, the slope continues to decrease somewhat, with an average $r$ of about $0 \cdot 21$. Thus the variation of $n_{i} \phi_{i}$ with external osmolality follows equation (20) roughly, increasing about 12-fold as $m_{e}^{\prime}$ increases from 0.5 to 12.5 . Since some solutes may be precipitated at the lowest $\boldsymbol{R H}$ values within this region, the osmotic coefficient must increase by a larger factor than 12 and the increase must be due mainly to interactions involving the polymeric components and the non-solvent water (hydration).

Zones (5) to (7). Limited osmotic swelling leading to constant cell volume. When $m_{e}^{\prime} \sim 0.6$ there is a fairly abrupt transition to a third linear region with $r \sim 0.82$. This is the region of osmotic swelling. The behaviour deviates appreciably from the Boyle-Van't Hoff equation (Lucké \& McCutcheon, 1932), with $r$ differing from unity. If the osmotic coefficient is unity at the 'dilute' end of this linear zone, then it rises to 1.23 when the external osmolality is increased to 0.46 (Table 2).

If equation (18) were followed at external osmolalities below $0 \cdot 1$, the line in Fig. 4 would be extended until lysis occurred, perhaps with a shift in slope towards ideal behaviour $\left(\phi_{i}=1\right)$. Serratia marcescens and many other bacteria, however, are not lysed even by distilled water. Fig. 4 shows that there is a rather sharp 
transition from osmotic swelling to the maintenance of large internal hydrostatic pressures at constant volume.

The existence of the zone of constant cell volume was deduced by Mitchell \& Moyle (1956) from values of the volume of Escherichia coli inaccessible to inorganic phosphate in presence of different concentrations of $\mathrm{NaCl}$. The transition appeared to commence when $m_{e}^{\prime}$ was about $\mathbf{0 \cdot 4}$, but this conclusion rested upon a single experimental point; a recalculation shows that equation (18) is followed throughout, with $r \sim 0.5$ (Fig. 6). Our own measurements on E. coli (Fig. 5), agree with the recalculated Mitchell \& Moyle results and show also that the external osmolality must be reduced to about $0 \cdot 18$ before the slope of the line begins to fall off. The cell volume is constant when $m_{e}^{\prime}$ is less than $0 \cdot 1$.

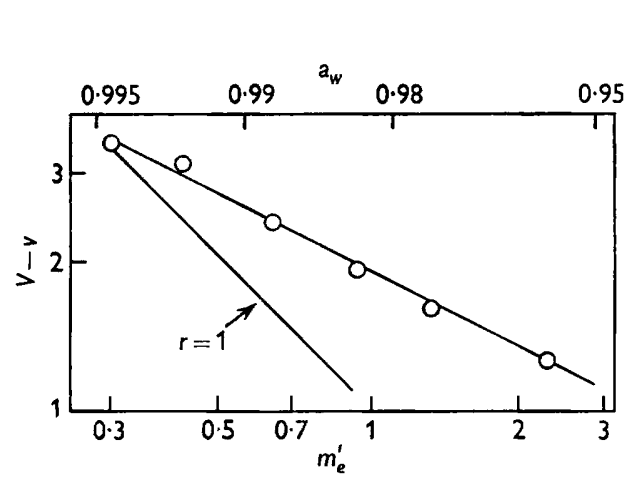

Fig. 6

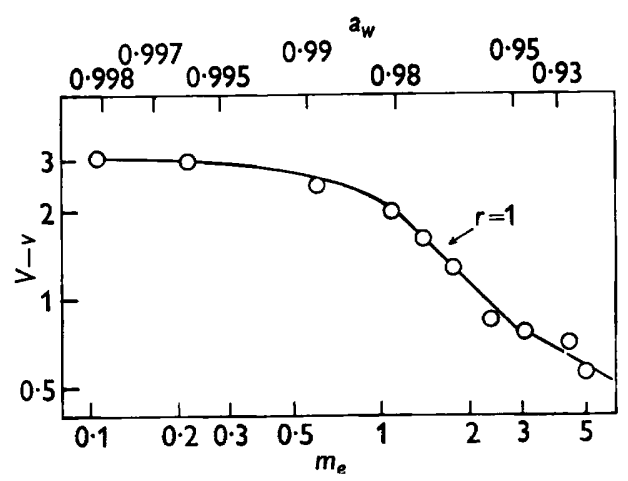

Fig. 7

Fig. 6. Water volume of one gram dry Escherichia coli as a function of environmental osmolality, from volume measurements in $\mathrm{NaCl}$ solutions using inorganic phosphate as tracer. Values of phosphate impermeable volume estimated from Mitchell \& Moyle's (1956) graph, their Fig. 4, and corrected for the fact that the cell wall contributes to the dry weight but does not participate in the osmotic movement of water. The correction factor $f$ (equation 16) was taken to be $\mathbf{1 . 5 2}$, determined as described in this paper.

Fig. 7. Water volume of one gram dry Staphylococcus aureus at different relative humidities. Data of Mitchell \& Moyle (1956), given in their Fig. 1 as a plot of weight of cell sample against reciprocal of the molality of the sucrose solution used to control the $R H$. Values read from this curve were corrected for dry weight of cell sample, taken as $47 \mathbf{m g}$, and for osmotic coefficient of water in sucrose solutions (Scatchard et al. 1938).

Limiting cell volume in vapour phase equilibration. In vapour phase equilibration of osmotically resistant cells, the increase of internal hydrostatic pressure must always be such as to bring the vapour pressure of the cell into equilibrium with the atmosphere; the water content must remain nearly constant until the atmosphere becomes fully saturated. At this point the cell is in equilibrium with both liquid water and water vapour and the equilibrium water content of the system is indeterminate. In the presence of a trace of external solute, however, it is infinite, and uptake of water in a saturated or slightly undersaturated atmosphere will proceed indefinitely. The predicted levelling-off of water content in vapour phase equilibration has been found for Staphylococcus aureus by Mitchell \& Moyle (1956), starting when $m_{e}^{\prime}$ is about $\mathbf{0 \cdot 6}$ (Fig. 7). At lower $\boldsymbol{R H}$ values there is, as with Serratia marcescens, an ideal region succeeded by one of increasing osmotic coefficient.

Solute content of bacteria. The values of $n_{i}$ (Table 2) indicate the amounts of 
osmotically active solutes per g. dry cells, while the values of $m_{e}^{\prime}$ at the limiting (maximum) cell volume give the internal osmolality. It is of interest that Mitchell \& Moyle's Escherichia coli, grown in a salt-glucose medium, contained four times as much dissolved substance as ours, grown in nutrient broth of low salt content. Staphylococcus aureus contains much more dissolved material than $\boldsymbol{E}$. coli or Serratia marcescens $-1.49 \mathrm{~m}-\mathrm{mole} / \mathrm{g}$, and a limiting internal osmolality of 1.0 . It is surprising that the apparent osmotic coefficient remains constant over a three-fold range of $m_{e}^{\prime}(\mathbf{1} \cdot \mathbf{0}$ to $\mathbf{3} \cdot \mathbf{0})$.

Relative humidity and the stability of air-borne bacteria. At several points the interpretation of the water uptake curve of Serratia marcescens is speculative and at others incomplete. Nevertheless, there is relevance to the problem of stability of air-borne bacteria: (1) The existence of inflexions in the curve invites more detailed interpretation and comparison with stability data (Monk, McCaffrey \& Davis, 1957). (2) The hysteresis-like retention of water during desorption suggests that bacterial stability may depend upon the history of the particle, especially upon the direction of water transfer. A more detailed study might reveal slow irreversible changes in the dehydrated organisms or the existence of potential energy barriers, e.g. supersaturation, failure to dissolve, formation of cross-linked structures which do not expand reversibly on wetting, capillary effects of the type discussed by Hill (1952). R. M. Izatt \& T. Hatch (to be published) have shown clearly the effects of relatively gross amounts of hygroscopic additives in modifying the water uptake curves. (3) Clearly the curve of Fig. 4 does not represent a series of true equilibria, for metabolic processes continue (Monk et al. 1957) and viability is gradually lost. Despite the enormous retardation of these processes, however, there must be zones of water content within which the diffusion rates of intracellular molecules or polymeric submolecules become sharply dependent upon $R H$; one such region presumably would be within the overlapping zones of non-ideal solution and of failing co-operative multilayer adsorption. Here one might well seek special biological effects, arising perhaps from random translocations of specific molecules present in statistically small numbers. (4) Comprehensive data such as those in Fig. 4 are required in any theoretical study of air-borne organisms since rates of 'equilibration' with an atmosphere will depend partly upon the amounts of water to be transferred for a given change of $R H$. The differential amounts, $d V / d a_{w}$, vary by more than 2 orders of magnitude between $R H \quad 0$ and $100 \%$.

\section{REFERENCES}

Ashrole, D. K. (1932). The moisture relations of textile fibres at high humidities. Proc. roy. Soc. A, 212, 112.

Boltz, D. F. \& Mellon, M. G. (1947). Determination of P, Ge, Sn and As by the heteropoly blue method. Industr. engng Chem. (Anal. Ed.) 19, 873.

Brice, B. A. \& Halwer, M. (1951). A differential refractometer. J. opt. Soc. Amer. 41, 1033.

Brunauer, S., Emmett, P. H. \& Teller, E. (1938). Adsorption of gases in multimolecular layers. J. Amer. chem. Soc. 60, 309.

BuLl, H. B. (1944). Adsorption of water vapor by proteins. J. Amer. chem. Soc. 66, 1499.

De Boer, J. H. (1956). Adsorption in catalysis. Advanc. Catalys. 8, 16.

Drck, D. A. T. (1959). Osmotic properties of living cells. Int. Rev. Cytol. 8, 387.

Guggenherm, E. A. (1957). Thermodynamics. New York: Interscience. 
Halsey, G. (1948). Physical adsorption on non-uniform surfaces. J. chem. Phys. 16, 931. Hill, T. L. (1952). Theory of physical adsorption. Advanc. Catalys. 4, 211.

Imelik, B. (1951). Étude de l'adsorption de l'eau par les bactéries. Ann. Inst. Pasteur, $81,562$.

Lucké, B. \& McCutcheon, M. (1932). The living cell as an osmotic system and its permeability to water. Physiol. Rev. 12, 68.

McBain, J. W. \& Bakr, A. M. (1926). A new sorption balance. J. Amer. chem. Soc. 48, 690.

Mitcheld, P. \& Moyle, J. (1956). In Bacterial Anatomy: Symp. Soc. gen. Microbiol. 6, 150.

Monk, G. W., McCaffrey, P. A. \& Davis, M. S. (1957). Studies on the mechanism of sorbed water killing of bacteria. J. Bact. 73, 661 .

Scatchard, G., Hamer, W. J. \& Wood, S. E. (1938). Isotonic solutions. I. The chemical potential of water in aqueous solutions of sodium chloride, potassium chloride, sulfuric acid, sucrose, urea and glycerol at $25^{\circ}$. J. Amer. chem. Soc. 60, 3061 .

Stokes, J. M. (1945). The osmotic and activity coefficients of sodium and potassium dihydrogen phosphate at $25^{\circ}$. Trans. Farad. Soc. 41, 685. 
